\title{
PENSANDO O “OUTRO” E A CONSTRUÇÃO IDENTITÁRIA NA SOCIEDADE CONTEMPORÂNEA ${ }^{1}$
}

\author{
Elizete Conceição Silva ${ }^{2}$
}

\author{
"Reconhecer nossos próprios erros e \\ pontos fracos nos dá condiçōes de nos \\ envolvermos num desafio pessoal e promover \\ uma transformação moral/.../"
}

(TODOROV, 2001, p.8)

\section{RESUMO}

Na investigação de como se dá o processo da construção identitária do sujeito e apoiando-se na questão cultural e seus desdobramentos, tais como alteridades, simbolizações, e considerando que na sociedade contemporânea, frente ao fenômeno da globalização, presencia-se reinvenções culturais. O social se reestrura e se reapresenta sobre novos valores como por exemplo: a volatilidade, a flexibilidade e a fluidez, ambos tão exacerbados na comtemporaneidade. Pensando a nova ordem social frente ao fenômeno da globalização e as transformações que esta a cada dia coloca à nossa frente, o indivíduo em sua singularidade também tem que se reestruturar, se readequar aos novos tempos. Promovendo um recorte nas relações produtivas, o indivíduo nesse momente de restrutação da produção, ao qual é exigido uma flexibilidade tanto a nivel coletivo como pessoal, passa por transformações identitárias, não se reconhecendo frente aos novos valores culturais. Analisar como ocorre esse processo de re-construção identitária e suas implicações na determinação de se colocar como agente da própria vida ou como vítima do sistema é o que o artigo propõe a refletir.

palavras-chave: globalização, identidade, cultura, vitimização

\section{THINKING THE "OTHER" AND THE IDENTITY CONSTRUCTION IN THE CONTEMPORARY SOCIETY}

\footnotetext{
ABSTRACT

This article aims to analyse the process of transformation and construction of the identity, taking as basic element the cultural question, such as alterity and symbolizations. The globalization challenge the individuals with new values like volatileness, flexibility and the fluidity and these values are

' Esse artigo é fruto de reflexões e pesquisas que vem sendo desenvolvidas no transcorrer do doutorado e faz parte de uma discussão em torno do quadro conceitual para estudo sobre a relação entre identidade, individuo e processo de vitimização relacionado a reestrutuaçâo no sistema produtivo, com recorte sobre os Programas de Demissão Voluntária (PDV).

2 Socióloga, doutoranda em Ciências Sociais pela PUC-SP
} 
transformed into the scope of the industrial relations, demanding more personal flexibility and new transformations of individual identity. In order to explain the reconstruction of the individual identity the article focuses on the implications of this cultural transformation in the modern society.

Keywoords: globalization, identity, culture, victim

Inquerindo a respeito de como recuperar denominações e seus respectivos significados, valores e atuação nas sociedades contemporâneas, tais como: sentimento, inveja, ressentimento, felicidade, amor, palavras tais que talvez não se dê a devida importância, e/ou talvez não sejam questionadas por um ângulo mais relevante do que as denominações, ou seja, a respeito de suas representações e atuações na apresentação da sociedades, a pesquisa encaminhou-se para buscar na psicanálise instrumentais de análise do indivíduo.

O interesse de interpretar como a cultura atua na construção identitárias, conduz ao problema sobre como, na sociedade contemporânea, apresenta-se a questão das alteridades, e indaga-se se essas questões primeiramente apresentadas não contribuiriam para se pensar no modo como o sujeito pode estar se sentindo, se colocando, atuando ou se re-criando no momento de re-inclusão produtiva ${ }^{3}$.

Ao se avançar um pouco mais nas indagações, questiona-se: qual (is) poderia $(\mathrm{m})$ ser a $(\mathrm{s})$ alternativa(s) do sujeito frente às formas de apresentação da sociedade (político-econômica e social) de interação ao outro, de modo a negar a lógica apresentada, buscando sua re-criação de forma ativa, participante e não se vitimizando, colocando-se como um não entendido, como alguém sofredor, imputado. Apresentando-se como alguém que, não tendo coragem de aceitar seus limites, suas necessidades, seus fracassos, passa a se ver e quer ser visto como vítima. Pensam e dizem o tempo todo: "impuseram-me essa situação", "a que ponto cheguei", "não me entendem", e por diante. Não atentam para o fato de que o mundo não vai parar por causa da sua condição de vítima. Não percebem que devem buscar entender o mundo e buscar um modo de se inserir e de acompanhar as transformações. A sociedade não pode se estruturar com base em particularismos, mas sim no universal.

A sociedade não está pronta, a cultura não está pronta, o homem não está pronto. Tanto a sociedade, a cultura, o homem estão em um constante movimento, é um constante vir-a-ser, enfim é um constante re-criar-se.

Indaga-se neste momento se estaria o posicionamento do sujeito reforçando e comprovando a hipótese de que o sujeito da sociedade contemporâ-

\footnotetext{
${ }^{3}$ Considera-se o momento em que o individuo tenta retornar e adaptar-se aos "novos" moldes do mundo do trabalho frente as relações promovidas pela globalização.
} 
nea construiu o espaço e tornou-o mais aceitável, passando a ocupá-lo de forma acomodada - a condição de vítima e que, enquanto vítima, sujeito a ser ressarcido de algo que perdeu, o que acredita ter perdido, seja respeito, segurança, ou bens materiais. Deste modo, a possibilidade de fechar-se com seus semelhantes, de não aceitar as diferenças estaria se fortalecendo, e a possibilidade de se re-inventar tornar-se-ia mais complicada, porém, não impossível. Mas para tal acontecimento, o sujeito teria que re-estabelecer um elo entre o passado e o futuro, o presente puro e simples não abre possibilidade de um projeto possível, além da necessidade de reconhecer a existência do outro.

Considerando que se presencia uma sociedade de des-simbolização, como o indivíduo se re-coloca em uma sociedade onde os valores, as representações passam a ser voláteis, onde todos os sentimentos são passados como ilegítimos, onde devido a rapidez das transformações, se ele não agir de pronto, o OUTRO agirá sobre ele. Como vivenciar esse outro, e quem pode ser esse outro no dia-a-dia?

Tem-se muito a refletir em relação a sociedade contemporânea, ao fenômeno globalização, ao papel do imaginário e das reinvenções culturais, para buscar compreender um pouco mais a respeito das re-construções identitárias. A cultura global individualizou o sujeito, e proporciona a cada dia um maior número de construções identitárias. Uma das alternativas que passou-se a adotar é o retorno às tribos, o retorno aos iguais. Criam-se comunidades imaginadas, nas quais os sujeitos se reconhecem, e passam a se ver no outro, criando um "fechamento", um isolamento, um eterno olhar-se no espelho o processo de vitimização.

O sujeito é marcado pelas representações sociais, e a sua inclusão ou não passa tanto pelo campo do econômico, político e social como pelo campo do imaginário.

Pensando essas questões, busca-se a contribuição da psicanálise para se entender as transformações no processo social, o politico, de modo a se instrumentalizar conceitualmente a reflexão sobre a tríade: sujeito - social sujeito, ou seja: buscar o entendimento de como o sujeito (indivíduo) vivendo em coletividade (social) retornar a si mesmo (indivíduo), como se sente e age enquanto ser, enquanto pessoa. Como o coletivo (o social) marca o indivíduo.

A partir desta abordagem, torna-se mais visivel que as relações sociais na sociedade contemporânea estão construídas sobre um apego e uma busca incessante pela felicidade. Fala-se da felicidade enquanto direito de todos, passando-a para o campo do direito. A felicidade já não depende do sujeito, mas é algo exterior, algo que ele necessariamente deverá ter e obterá sem 
necessariamente lutar, ou ao menos buscar. Ela é sua, e não poderá ser retirada.

Acontece que felicidade é uma subjetividade. Talvez pudesse falar em um estado de espírito. Assim sendo, como alguém pode nos garantir algo tão pessoal, algo que acontece no nivel interior? Como obtê-la - a felicidade - pronta, acabada, quando ela é algo a ser construído?

Ai encontra-se um obstáculo para o indivíduo. Ele passa a esperar que o exterior supra o seu interior, ele passa a ter a necessidade de ser feliz, sendo que alguém ou algo deverá suprir essa necessidade.

A necessidade apresenta um objeto de satisfação. Logo, o indivíduo passa a buscar a sua felicidade no consumo. De acordo com Bauman ${ }^{4}$, o consumo passa a ser condição para a felicidade e talvez até para a dignidade humana.

O individuo nas sociedade contemporânea, por não conseguir ver o outro, apresenta um ego inflamado, não se dá conta de que não existe sozinho, de que para ele existir tem que haver o reconhecimento do outro.

A partir do momento que o individuo passa a acreditar que o seu bemestar, encontra-se em bens materiais, em bens de consumo, ele fecha-se, pois não vê necessidade de conviver com um outro que pode apresentar semelhanças, mas que também apresentará diferenças, o que exigirá dele a colocação de limites, para que o convívio ocorra. Parte em busca da aquisição do que naquele momento determinou como necessário, desta forma, o seu objetivo é individual, rompe com o coletivo, tudo passa a ser permissivo, logo, não há regras, valores, símbolos que servirão de obstáculo para sua missão ser feliz.

Considerando a dinamicidade da cultura, os valores que vão absorvendo os sujeitos na sociedade atual, sofrem contribuição do fluxo mediático. Por meio dos meios de comunicação, propagam-se idéias, constroem necessidades e em última instância, possibilitam construções identitárias. De que modo que isso pode acontecer?

Em primeira instância constrói imagens, pensamentos, relacionandoos a um determinado produto que sendo consumido pode lhe proporcionar algo tão belo quanto as imagens promovidas. Cada indivíduo se sentirá compelido por um determinado motivo (sucesso, felicidade...) para sua aquisição, a qual torna-se necessária. Esse quadro favorece o desaparecimento do indivíduo (enquanto subjetividade), ele passa a ser guiado, suas necessidades, seu desejo, passa a ser despertado, a partir de algo exterior a ele mesmo e,

${ }^{4}$ BAUMAN, Zygmunt. O mal-estar da pós-modernidade. Rio de Janeiro: Zahar, 2004. pp. 55.56 
não se dando conta do que ocorre, devido a rapidez das transformações. $\bigcirc$ sujeito passa a ser o que a sociedade oferece como ideal, o seu campo de ação intersubjetiva é destruído.

A sociedade da mídia e do consumo de bens efêmeros, pereciveis e descartáveis engendra uma subjetividade de tipo novo, o sujeito narcisista que cultua sua própria imagem como única realidade que lhe é acessivel e que, exatamente por ser narcisica, exige aquilo que a mídia e o consumo lhe prometem sem cessar, isto é, satisfação imediata dos desejos, a promessa ilimitada de juventude, beleza, sucesso e felicidade que lhe virão por meio dos fetichizados, promessas que, no entanto, não podem se cumprir gerando frustração $e$ niilismo ${ }^{5}$.

De acordo com Enriquez ${ }^{6}$, a cultura é composta de um sistema cultural, um sistema simbólico e de um sistema imaginário, este composto pelo imaginário motor e o imaginário enganoso. $O$ primeiro apresenta-se como um desafio às regras de funcionameno da sociedade, pois faz ressurgir a categoria do diferenciado. "/.../. O imaginário motor preserva /.../ a parte do sonho e a possibilidade de mudança ou mesmo de mutação" (p.93). Ele "/../ favoriza a criatividade feliz, a palavra livre, o pensamento enquanto capacidade de tudo questionar, de tudo transgredir, o desejo de construir objetos estéticos, o prazer de reencontrar o outro em sua singularidade e ao prazer de conviver /.../. " (p.93-4).

Deste modo e ainda de acordo com o autor, o imaginário motor constitui um verdadeiro desafio as sociedades humanas, devido essas preferirem a constância à mudança e ainda, que devido a dificuldade de deixar o campo livre para esse imaginário, a tendência é recorrer ao imaginário enganoso.

Quando isso ocorre, a sociedade se engana e passa a buscar a unicidade de identidade, o narcisismo exacerba-se, não se vê mais o semelhante, e, surgem o que denominam de "estranhos".

Os estranhos então seriam aqueles seres humanos que transgridem os limites, eles são voláteis, instáveis, um eterno recomeçar. De acordo com Bauman (2004,p.37) "/.../. Os estranhos de hoje são subprodutos, mas também os meios de produção no incessante, porque jamais conclusivo, processo de construção da identidade".

O reconhecimento da alteridade é problemático, e tem um longo caminho a ser percorrido. Para Enriquez ${ }^{7}$,

${ }^{5}$ CHAUÍ, Marilena. Ética e violência. Revista Teoria e Debate. Out/nov/dez 98. p.34

${ }^{6}$ ENRIQUEZ, Eugène. Caminhos para o outro, caminhos para si. Revista Sociedade e Estado. Vol.IX, ns.1-2, jan./dez. 2004. p. 109

${ }^{7}$ ENRIQUEZ, Eugène. op. cit. p. 104 
"/... o caminho para o outro, para a aceitação de outras culturas, com as quais podemos dialogar, é muito longo. É um processo interminável /.../. O trabalho de transformação é, por isso, um trabalho sem fim, que exige igualmente mudanças radicais no psiquismo humano e no psiquismo social, mesmo considerando os limites inerentes a uma tal transformação/.../".

Pode-se constatar que o modo de apresentação da contemporaneidade, favorece a homogeneização de identidade, trazendo consigo um não olhar ao outro, pois o outro lembra que não se está sozinho, que a sua identidade individual e coletiva não está assegurada, que existem outras culturas que não a sua, enfim, o outro é sempre potencialmente perigoso Enriquez ${ }^{8}$.

Retornando a reflexão inicial no tocante ao processo de vitimização. Considerando que o outro é um perigo para sua sobrevivência, para a sua realização, seu sucesso e felicidade, uma alternativa promovida pelo sujeito é a de retorno às tribos, retorno aos iguais. Um total fechamento e desconsideração à existência das diferenças.

Se o mundo já não me entende, busco um lugar onde serei entendido. Não há uma relação, não se reconhece o seu próprio papel na construção desse mundo. Se colocando enquanto vítima, ele retira todo o potencial de ação de tuas mãos e passa a um outro, a um outro que ficará na condição de piedoso, logo, o sujeito se abstém de seu papel de sujeito de direito passando a ser objeto de compaixão.

Como observa ${ }^{9}$

/... A pessoa deixa de ser vítima dos riscos e responsabilidades relacionadas ao engajamento em seu desejo, sua vida, e se torna vítima de circunstâncias desfavoráveis, o que vai constitui-la em um sujeito traumatizado e não mais num sujeito engajado em sua própria vida, com todos os riscos decorrentes do exercício de seu desejo.

Seguindo esse raciocínio, a vítima se ressente. Ela quer (deseja) o que o outro tem, ela sente inveja do outro e se coloca na posição de sujeito de direito a ter o que o outro possui. As ideologias do ressentimento não consideram os deveres, mas se afirmam no registro dos direitos. Novamente, a vítima se coloca como tal porque o discurso atual se fundamenta nos direitos, em nenhum momento se exalta os deveres de cada um consigo mesmo e com a própria sociedade, ou mesmo o direito do outro, o outro não é reconhecido como sujeito de direito.

\footnotetext{
${ }^{8}$ Idem.

9 KOLTAI, Caterina. Uma questão tão delicada. Revista Psicologia Clinica, vol.14, n.2,, Rio de Janeiro, 2002. p. 40
} 
O ressentimento é característico da era dos particularismos. Em sociedade não se deve e não se tem como garantir o particular, mas é o universal que tem que ser garantido. $O$ pessoal, o singular tem que ser buscado e garantido em nivel individual, porém, em estreita relação com o coletivo, ou seja, considerando as representações sociais. No entanto, como tão bem Chauí ${ }^{10}$ colocou a respeito da forma atual de acumulação flexível, ela destrói " /.../ seus antigos referenciais de identidade e de ação tornando altamente complicada a criação de novos referenciais, de tal maneira que a fragmentação e a dispersão tendem a aparecer como naturais e a se oferecer como valores positivos".

Nesse momento, ao retornar a reflexão inicial - re-construção de identidades no momento de re-inclusão produtiva - e considerando as falas de alguns entrevistrados de SILVA ${ }^{11}$, constata-se que em alguns momentos se presencia a vitimização por parte do excluído/afastado do trabalho $\left(\mathrm{PDV}^{12}\right)$. Essa posição de vítima está presente na fala daqueles que não conseguiram se re-construir, acreditando que o que lhes foi dito no momento de afastamento era uma promessa e algo certo a ser recebido. Não vendo a necessidade de ação, esperou-se enquanto "direito" uma vida feliz e de sucesso.

No entanto, para outros, que através de atitudes, encararam a nova situação enquanto possibilidade de se recriarem, buscaram atuar de maneira diferente dentro de um contexto e de uma realidade que não presenciavam (competitividade, flexibilidade, potencialidade) com tanta evidência, devido considerarem "seguros" em seus ambientes de trabalho.

Desta forma, os primeiros - o vitimizado - vêem o fracasso como prova de que os outros continuam lhes atrapalhando e que estão com a razão. O "vitimizado" vai se ressentindo, e para se consolar fortalece sua maneira de pensar a vida, e a cada momento ignora um pouco mais a existência do outro enquanto seu semelhante.

Cria-se uma união instável, volátil, mas significativa, a medida em que esse sujeito se abstém de pensar o seu dever e fica na instância de direito, do que te prometeram, ele necessitará de iguais para se fortalecer, a visão do outro que "deu certo", do outro que possui algo que ele acreditava ser certo que teria, esse outro o sufoca, o deprime, ele precisa destruir esse outro, e de que modo? Uma das maneiras é criando uma rede de pessoas que sintam e

\footnotetext{
10 CHAUÍ, Marilena. op. cit

" SILVA, Elizete Conceição. Tempo Produtivo: reconstruindo identidades. Dissertação de Mestrado apresentada ao programa de Pósgraduação em Ciências Sociais da Universidade Estadual de Londrina, 2002. mimeo.

12 PDV - programa de demissão voluntária. Implantado como estratégia de reestruturação produtiva - "enxugamento do quadro funcional".
} 
pensem da mesma maneira, de modo que o outro passará a não existir, porque o ignora a medida em que sente-se pleno entre os iguais.

No entanto, reportando-me ainda as entrevistas acima citadas, constata-se que alguns conseguem romper com essa visão e começar a aos poucos a caminhar em direção à sua emancipação. Rompem com a inércia, tomam as rédeas de suas vidas e percebem que o que lhes é acenado não é o de direito, no máximo o de possibilidade e que para alcançar a meta - o sucesso - a felicidade, cada um da sua maneira terá que buscar sua alternativa.

Convém ressaltar que essa alternativa não será idêntica em todas as localidades e em todos os momentos, mas será um constante re-inventar. Com a globalização, as transformações estruturais (econômica, politica e social), o modo de viver, de organizar-se em sociedade e de interação sofreram bruscas modificações e o indivíduo necessita readequar-se ou ao contrário não passará de mero espectador e consumidor.

Nesse momento de re-construção, o sujeito desconstrói o que para ele encontrava-se pronto, e esse é um momento doloroso, é uma dor que nem todos querem passar, pois a sociedade de hoje propaga o não sofrimento, a dor é inconcebivel, imoral, ilegítima. A sociedade é a da exaltação do prazer, da satisfação, da plenitude.

A re-construção promove a mudança de valores que em muitas casos, como o analisado - trabalho - encontra-se tão arraigado no ser do sujeito, em sua identidade que foi construida sobre sua relevância e necessidade, que o seu rompimento o desorienta. Surge a necessidade de re-criação de uma nova identidade, uma identidade que responda a realidade da sociedade contemporânea. Ele precisa tomar a direção de sua vida, mas, como pensar o sentimento de culpa de porque encontra-se nessa situação?

De acordo com Todorov ${ }^{13}$, para as vítimas é muito importante a reparação simbólica. "/.../é da reparação simbólica que a vitima mais precisa, tanto assim que a compensação material tem valor, entre outras razóes, devido ao reconhecimento simbólico que ela traz". As pessoas que se colocam em situação de sofrimento, de dor, sentem necessidade do reconhecimento do "mal", da "injustiça" que foram lhes causadas para que possam reconstruir suas identidades, é como se à partir de então sintam-se re-integradas na vida em sociedade.

É necessário tomar gosto pelo futuro. É preciso sentir a vida enquanto narrativa, passado e futuro, não se pode ficar apenas no presente, o presente individualiza, exacerba as paixões humanas tais como a inveja, maldade, o

\footnotetext{
13 TODOROV, Tzvetan. Ascenção do homem público. Caderno Mais, Folha de São Paulo, 18 de mar. 2001. p. 7
} 
ressentimento, precisamos resgatar o coletivo, as re-presentações sociais. É necessário re-aprender a dizer não.

Nesse momento passa-se a questionar a respeito do limite e da transgressão. A vida em sociedade coloca limites, mas, se o sujeito não buscar além dos limites não toma posse de sua autonomia. Como então indagar e refletir a respeito da transgressão? Se por um lado a transgressão o retira da unanimidade, construindo-o enquanto indivíduo, a transgressão rompe com a representação social (o valor simbólico), no entanto, o indivíduo enquanto ser social necessita do outro para que ele se reconheça enquanto homem, necessita de laços.

Esses laços seria a ligação do sujeito enquanto social, enquanto valores simbólicos apresentados pela cultura, os quais não são eternos ou a-históricos, mas produto e produtor de uma nova ordem, de uma nova organização social. Na sociedade contemporânea, esses laços se enfraquecem a cada momento. Exemplificando essa situação, reportando-se à inclusão produtiva, constata-se que quanto menor e mais fracos forem os laços sociais com o outro - enquanto semelhante - em um momento de re-inclusão, mais difícil torna a sua ação, ao contrário, se desconsiderar o outro e sua humanidade, suas necessidades, seus desejos, você se libera de qualquer sentimento de culpa em relação ao outro e, parte para o jogo do poder.

Finalizando, observou-se que a análise deste processo requer abordagens conceituais mais complexas e constata-se que as reflexões da psicanálise em relação ao indivíduo, contribuem para abrir outro caminho de indagações e de busca à compreensão de como pensar a reconstrução identitária no momento de re-inclusão produtiva, considerando como aquele que busca a re-inclusão produtiva, ele enquanto sujeito, enquanto ser social e novamente retornando a sujeito absorve, sente e se coloca frente a essa sociedade globalizada, sociedade que a todo momento promove a unicidade de identidades.

Encerra-se com uma citação de $\mathrm{ZIZEK}{ }^{14}$ "/.../O que torna a vida 'digna de ser vivida' é o próprio excesso de vida: a consciência da existência de algo pelo que alguém se dispõe a arriscar a vida (podemos chamar esse excesso de 'liberdade', 'honra', 'dignidade', 'autonomia', etc.). Somente quando prontos a assumir esse risco estamos realmente vivos /.../".

14 is ZIZEK, Slavoj. Bem-vindo ao deserto do real: estado de sitio. São Paulo: Bointempo, 2003, p. 109 